\title{
Protective effect of crude sulphated polysaccharides from Sargassum Swartzii (Turn.) C.Ag. against acetaminophen induced liver toxicity in rats
}

\author{
Khan Hira', Viqar Sultana ${ }^{1 *}$, Nasira Khatoon ${ }^{2}$, Jehan Ara ${ }^{3}$ and Syed Ehteshamul-Haque ${ }^{4}$
}

\begin{abstract}
Background: Polysaccharides from seaweeds have been reported to possess biological activities with potential medicinal value. Present study was aimed to investigate hepatoprotective effect of crude sulphated polysaccharides extracted from Sargassum swartzii against acetaminophen-induced liver injury.

Methods: The polysaccharides from S. swartzii was extracted at room temperature and at $70{ }^{\circ} \mathrm{C}$ and named as $\mathrm{EW}_{1}$ and $\mathrm{EW}_{2}$. These fraction was given orally to rats at $200 \mathrm{mg} / \mathrm{kg}$ body weight. Liver injury was induced by single intraperitoneal injection of acetaminophen. Hepatic marker enzymes; alanine aminotransferases (ALT), aspartate aminotransferases (AST), alkaline phosphatase (ALP), lactate dehydrogenase (LDH), bilirubin and other biochemical parameters; glucose, triglycerides, cholesterol, urea and creatinine were estimated in serum, while hepatic glutathione (GSH) and lipid peroxidation were measured in liver tissue. Histopathology of liver tissues was also carried out.

Results: Treatment with polysaccharides EW $\&$ EW 2 fractions significantly $(p<0.05)$ reduced the hepatic marker enzymes and other biochemical parameters along with increased GSH and reduced lipid peroxidation. The EW 1 fraction of crude sulphated polysaccharides produced hepatoprotection more or less equivalent to silymarin (35 mg/kg), a commercial herbal drug, while some parameters showed better results than silymarin. These results were further confirmed with histology of liver.

Conclusion: This study suggests that crude polysaccharides of S. swartzii has ability to protect against liver toxicity similar and/or better than silymarin (a standard drug) based on biochemical and histological findings. However toxicological studies would be recommended to evaluate any toxic effect of Sargassum swartzii.
\end{abstract}

Keywords: Sargassum swartzii, Sulphated polysaccharides, Hepatoprotective, Acetaminophen, Liver injury, Silymarin

\section{Introduction}

Liver is the vital organ and major metabolic hub of the body. An inflammation of liver cells is called hepatitis, if not controlled effectively then may leads to chronic liver diseases [1, 2]. A number of drugs have been used to treat liver diseases but their successful use in treating liver diseases is very small, because the drugs used for treating the liver diseases may have side effects [3]. The

\footnotetext{
* Correspondence: viqarsultana98@hotmail.com

${ }^{1}$ Biotechnology \& Drug Development Laboratory, Department of

Biochemistry, University of Karachi, Karachi 75270, Pakistan

Full list of author information is available at the end of the article
}

therapies based on natural substances are believed to be safer and better than drugs used in medical practices [4].

The marine environment is believed to be an incomparable reservoir of bioactive natural products, many of which exhibited structural features that have not been found in terrestrial plants [5]. In marine environment algae are of two types, microalgae and macroalgae [6]. Records showed that macroalgae (seaweeds) have been consumed in human diets particularly as a vegetable in Asia, since $600 \mathrm{BC}$ [7]. The Chinese used algae and seaweeds for medicinal purposes as early as $300 \mathrm{BC}$ [8]. The presence of reactive antioxidants (ascorbate and 
glutathione) along with carotenoides ( $\alpha$ - and $\beta$-carotene, fucoxanthin, astaxanthin), mycosporine-like amino acids (mycosporine-glycine) and catechins (e.g., catechin, epigallocatechin), gallate, phlorotannins (e.g., phloroglucinol), eckol and tocopherols was reported in seaweeds [9].

Phytochemicals from marine macroalgae are found to be effective non-toxic substances with wide variety of pharmacological activities [10, 11]. Seaweeds possess biological activities, such as cholesterol lowering, immunomodulatory, anti-hepatotoxic [12]. The polysaccharide from seaweeds specially agaro-oligosaccharides not only prevents the oxidative injury but also boosts host antioxidant enzyme system [13]. Sulphated polysaccharides from Laminaria japonica are able to repair damaged or hypofunctional organs and tissues by enhancing the production of immunoregulatory and proinflammatory cytokines [14]. Among different polysaccharides derived from brown and red seaweeds, sulphated polysaccharides (fucoidan) and lambda carrageenan exhibit hepatoprotective, antioxidant and free radical scavenging activity that might be due to their sulfur content [15] and molecular weight $[16,17]$. Seaweed, polysaccharide can be used for the development of new drugs due to its many biological activities [18]. The present study, further investigates the hepatoprotective effect of sulphated polysaccharides from Sargassum swartzii against acetaminophen (AAP) induced liver damage and associated complication.

\section{Materials and methods}

\section{Collection of seaweeds}

Seaweeds were collected at low tide from Buleji beach, Karachi coast. These seaweed species were washed thoroughly in order to remove salts, debris and epiphytes. Voucher specimens and herbarium sheets of the seaweeds were prepared and record (KUH-SW) was kept in the Seaweed Herbarium, MAH Qadri Biological Research Center, University of Karachi. Professor Dr. Mustafa Shameel (Department of Botany, University of Karachi) identified the seaweeds. Seaweeds were dried under shade, grinded and fine powder was used for experimental purpose.

\section{Extraction of polysaccharides}

The extraction of polysaccharides from seaweeds was carried out by slightly modified method of Ponce et al. [19]. The coarse powder of dry seaweeds $(100 \mathrm{~g})$ was extracted with $500 \mathrm{ml}$ of $80 \%$ ethanol first at room temperature and then at $70^{\circ} \mathrm{C}$ with constant stirring for $24 \mathrm{~h}$ in order to remove proteins, peptides, amino acids, vitamins, polyphenols, mannitols and other monosaccharides. The liquid portion was centrifuged off and residual seaweed was extracted with $250 \mathrm{ml}$ of water at room temperature and at $70{ }^{\circ} \mathrm{C}$ for $7 \mathrm{~h}$ with constant stirring and labeled as $\mathrm{EW}_{1}$ and $\mathrm{EW}_{2}$ fractions of crude sulphated polysaccharides respectively. The $E_{1}$ and $\mathrm{EW}_{2}$ fractions of crude sulphated polysaccharides were dried on Eyela FD-1, lyophilizer and stored at $-20^{\circ} \mathrm{C}$.

\section{Animals}

Healthy male albino rats of Wistar strain (140-170 g) were purchased from Dow University of Health Sciences, Karachi. All the animals were housed in prebedded polyethylene cages (3 rats/cage and 6 rats were used per group) with standard laboratory conditions (temperature $25 \pm 2{ }^{\circ} \mathrm{C}$ and $12 \mathrm{~h}$ light/dark cycle), fed with standard pellet diet and water ad libitum. The animals were kept in the laboratory for 1 week before starting the experiment to acclimatize animals with laboratory conditions.

\section{Induction of hepatotoxicity}

Acetaminophen (Sigma Aldrich, U.S.A.) was administered intraperitonealy@1 @ $/ \mathrm{kg}$, body weight and the dose was prepared in $40 \%$ polyethylene glycol (Sigma Aldrich, U.S.A.) with constant stirring and mild heating.

\section{Experimental design}

Group 1 received the distilled water daily for 14 days and served as normal control. Group 2 rats received distilled water daily for 14 days but injected with acetaminophen, $24 \mathrm{~h}$ prior to decapitation and served as AAP control. Group 3 orally administered with reference drug, sliymarin (Sigma Aldrich, U.S.A.) @ $35 \mathrm{mg} / \mathrm{kg}$ b.w. daily for 14 days. Group 4 and 5 received the $\mathrm{EW}_{1}$ and $\mathrm{EW}_{2}$ polysaccharide fractions of $S$. swartzii respectively ( $200 \mathrm{mg} / \mathrm{kg}$ b.w.) daily for 14 days. On last day, all the rats from group 2, 3, 4 and 5 received single intraperitoneal injection of acetaminophen. All the animals were fasted overnight and decapitated after $24 \mathrm{~h}$ of AAP injection. Normal control rats were injected with vehicle, 1 day before to decapitation.

\section{Assessment of hepatic damage}

Serum was separated from blood by centrifugation and used for the determination of alanine aminotransferases (ALT), aspartate aminotransferases (AST), alkaline phosphatase (ALP), lactate dehydrogenase (LDH), urea, creatinine, bilirubin, triglycerides, cholesterol and glucose using kits from Merck (France) and Ecoline (Germany). The liver tissue was excised immediately after decapitation and washed with ice cold normal saline. Homogenate $(10 \%)$ was prepared by homogenizing liver tissue with Tris $\mathrm{HCl}$ buffer (pH 7.4). Freshly prepared homogenate was used for the estimation of glutathione and lipid peroxidation. 


\section{Estimation of hepatic glutathione}

Reduced glutathione was estimated according to the method of Samarth et al. [20] with slight modifications. Homogenate $(0.1 \mathrm{ml})$ was mixed with $100 \mu \mathrm{l}$ of $25 \%$ trichloroacetic acid (TCA) and kept for $5 \mathrm{~min}$ at room temperature in order to precipitate protein. The mixture was centrifuged at $3000 \mathrm{rpm}$ for $10 \mathrm{~min} .0 .2 \mathrm{ml}$ of the supernatant was mixed with $1.8 \mathrm{ml}$ of $0.1 \mathrm{mM}$ DTNB (5,5'-Dithiobis-2-nitrobenzoic acid; in $0.3 \mathrm{M}$ sodium phosphate buffer $\mathrm{pH} 8$ ). The tubes were incubated for $10 \mathrm{~min}$ and absorbance was recorded against reagent blank at $412 \mathrm{~nm}$ using UV-visible spectrophotometer (He入IOS $\alpha$, Thermo Spectronic, UK). Mixture of all reagents except sample served as reagent blank.

\section{Estimation of lipid peroxidation}

The extent of lipid peroxidation was determined by quantifying the concentration of malondialdehyde (MDA) as described by Ohkawa et al. [21]. The tissue homogenate $(0.1 \mathrm{ml})$ was mixed with $0.1 \mathrm{ml}$ of $8.1 \%$ SDS and incubated for $10 \mathrm{~min}$ at room temperature. $750 \mu \mathrm{l}$ of $20 \%$ acetic acid ( $\mathrm{pH} 3.5)$ and $750 \mu \mathrm{l}$ of $0.8 \%$ thiobarbituric acid (TBA) were added and volume was adjusted to $2 \mathrm{ml}$ with water. The tubes were placed in water bath at $95^{\circ} \mathrm{C}$ for $60 \mathrm{~min}$ and cooled under tap water. The final volume was adjusted to $2.5 \mathrm{ml}$ with distilled water. The same volume of butanol and pyridine (1:1) mixture was added in each tube, vortex and centrifuged at $4000 \mathrm{rpm}$ for $10 \mathrm{~min}$. The upper organic layer was removed and absorbance was recorded against reagent blank at 532 $\mathrm{nm}$ using UV-visible spectrophotometer.

\section{Hepatic histology}

A small portion of liver tissue was fixed in formalin (5\%) and kept in laboratory for $48 \mathrm{~h}$. Tissue was embedded in paraffine in order to cut sections of 3 to $4 \mu \mathrm{m}$ thick and stained with hematoxylin and eosin ( $\mathrm{H} \& \mathrm{E})$ staining solutions. The extent of damage was assessed by using microscope (Nikon FX-35A, Japan) at 100X and 200X.

\section{Statistical analysis}

Data was analyzed and subjected to Analysis of Variance (ANOVA) and means were separated using Duncan's multiple range test (DMRT) according to Armitage \& Berry [22]. $P$-value $<0.05$ was considered as a level of significance.

\section{Results}

Effect of $\mathrm{EW}_{1}$ \& $\mathrm{EW}_{2}$ fraction of $S$. swartzii on serum markers in acetaminophen intoxicated rats

Serum ALT, AST, ALP, LDH and bilirubin values of normal control rats were $27 \pm 1.7,88 \pm 8,45 \pm 6.2,238.6$ \pm 10.2 and $0.56 \pm 0.057$ respectively. Acetaminophen administration raised the levels of these enzymes as compared to control $(64 \pm 7.8,187.6 \pm 9.29,124 \pm 4.3$, $542.6 \pm 17.6$ and $0.93 \pm 0.054$ respectively). Liver is major metabolic hub of body and controls complete body metabolism. If liver is injured by any toxic substance then glucose, triglyceride, cholesterol, urea and creatinine levels would also be disturbed in blood. As evident from this study; acetaminophen intoxication significantly $(p<0.05)$ elevated the levels of glucose, triglyceride, urea and creatinine as compared to normal control rats. Treatment with crude sulphated polysaccharides $\left(\mathrm{EW}_{1}\right.$ and $\mathrm{EW}_{2}$ ) fractions of Sargassum swartzii significantly $(p<0.05)$ reduced the elevated level of ALT, AST, ALP, LDH and bilirubin along with other metabolites glucose, triglyceride, urea and creatinine. The more potent activity was found in crude sulphated polysaccharides extracted at room temperature (EW ${ }_{1}$ fraction) of Sargassum swartzii with reduced ALT $(33.3 \pm 2.5)$, AST (121 \pm 12.5$)$, ALP $(47.6 \pm 1.5), \mathrm{LDH}(318 \pm 10.5)$, bilirubin $(0.76 \pm 0.06)$, glucose $(127 \pm 7.5)$, triglycerides $(108 \pm$ $17.08)$, urea $(38.6 \pm 2.5)$ and creatinine $(1 \pm 0.1)$. The effect was more or less equivalent to silymarin $(35 \mathrm{mg} / \mathrm{kg})$ while some parameters showed better results than silymarin. The rats pretreated with crude sulphated polysaccharides extracted at $70^{\circ} \mathrm{C}\left(\mathrm{EW}_{2}\right)$ fraction of Sargassum swartzii also showed hepatoprotective activity (Tables 1 and 2) but at lower extent. The silymarin (35 $\mathrm{mg} / \mathrm{kg}$ ) also protected the liver from being injured by acetaminophen, evident by significant $(p<0.05)$ decreased in ALT, AST, ALP, LDH, bilirubin.

\section{Effect of $\mathrm{EW}_{1} \& \mathrm{EW}_{2}$ fraction on glutathione (GSH) and lipid peroxidation}

Oxidative stress was confirmed by observing hepatic reduced glutathione (GSH) status in rats administered with AAP alone $(8.16 \pm 0.75 \mu$ mole/gm wet liver tissue $)$ as compared to normal control rats $(14.7 \pm 1.1 \mu \mathrm{mole} /$ gm w.l.t.). The significant improvement was found in rats pretreated with $\mathrm{EW}_{1}$ fraction of $S$. swartzii $(14.8 \pm$ $0.15 \mu \mathrm{mole} / \mathrm{g}$ wet liver tissue) followed by acetaminophen administration and this is almost equal to normal control rats. The $\mathrm{EW}_{2}$ fraction ameliorated the acetaminophen-induced reduction in reduced glutathione level to $13.7 \pm 0.321 \mu \mathrm{mole} / \mathrm{gm}$ w.l.t. but was not too much effective (Fig. 1).

Administration of AAP induced significant increase in lipid peroxidation as observed in high concentration of TBARS as compared with normal control rats. However significant decline in TBARS level was found in rats pretreated with $\mathrm{EW}_{1}$ and $\mathrm{EW}_{2}$ fraction of $S$. swartzii following the acetaminophen intoxication. But good protective effects were observed in $\mathrm{EW}_{1}$ fraction of $S$. swartzii followed by $\mathrm{EW}_{2}$ fraction of S. swartzii (Fig. 1). The crude sulphated polysaccharides $\left(\mathrm{EW}_{1}\right)$ fraction of S. swartzii restored hepatic glutathione level and reduced 
Table 1 Effect of Crude Sulphated Polysaccharides of Sargassum swartzii on Liver Enzymes and Bilirubin in Acetaminophen-Intoxicated Rats

\begin{tabular}{llllll}
\hline Groups & ALT (U/L) & AST (U/L) & ALP (U/L) & LDH (U/L) & Bilirubin (mg/dl) \\
\hline Normal control & $27^{\mathrm{d}} \pm 1.7$ & $88^{\mathrm{d}} \pm 8$ & $45^{\mathrm{c}} \pm 6.2$ & $238.6^{\mathrm{d}} \pm 10.2$ & $0.56^{\mathrm{c}} \pm 0.051$ \\
Acetaminophen (AAP) control & $64^{\mathrm{a}} \pm 7.8$ & $187.6^{\mathrm{a}} \pm 9.29$ & $124^{\mathrm{a}} \pm 4.3$ & $542.6^{\mathrm{a}} \pm 17.6$ & $0.93^{\mathrm{a}} \pm 0.054$ \\
Silymarin (35 mg/kg) + AAP & $37.3^{\mathrm{bc}} \pm 4.5$ & $139^{\mathrm{bc}} \pm 8.88$ & $68.3^{\mathrm{b}} \pm 7.5$ & $375^{\mathrm{b}} \pm 17.5$ & $0.76^{\mathrm{b}} \pm 0.056$ \\
S. swartzii EW + AAP & $33.3^{\mathrm{cd}} \pm 2.5$ & $121^{\mathrm{c}} \pm 12.5$ & $47.6^{\mathrm{c}} \pm 1.5$ & $318^{\mathrm{c}} \pm 10.5$ & $0.76^{\mathrm{b}} \pm 0.06$ \\
S. swartzii EW $\mathrm{EW}_{2}$ AAP & $45^{\mathrm{b}} \pm 4$ & $154^{\mathrm{b}} \pm 14$ & $60.3^{\mathrm{b}} \pm 0.57$ & $375^{\mathrm{b}} \pm 17.5$ & $0.73^{\mathrm{b}} \pm 0.052$ \\
\hline
\end{tabular}

The values are expressed as means \pm Standard error ( $n=6$ animals per group)

The values having the same superscript within the column are not significantly $(p<0.05)$ different according to Duncan's multiple range test

hepatic lipid peroxidation almost near to the standard drug (silymarin).

\section{Effect of crude Sulphated polysaccharides fractions $\left(\mathrm{EW}_{1} \& \mathrm{EW}_{2}\right)$ on hepatic histology}

Histopathological examination of normal rats showed normal lobular structure. Central vein, portal triads, hepatic sinusoids and cells were normal (Fig. 2a). The rats treated with acetaminophen (AAP) showed prominent hepatic necrosis, abnormal architecture of central vein and dilated sinusoidal structure can be observed. Cells possess vesicular structure in their cytoplasm. Infiltration of macrophages and polymorphonuclear cells were observed (Fig. 2b). Treatment with $\mathrm{EW}_{1}$ fraction of $S$. swartzii healed the hepatic injuries. The inflammatory cells are very rare with normal sinusoidal pattern (Fig. 2c). Histopathological examination revealed that no fatty changes were observed in rats pretreated with $\mathrm{EW}_{2}$ fraction of S. swartzii prior to acetaminophen intoxication. Very few vacuolization was seen in the cells. However some inflammatory cells and polymorphnuclear cells can be seen, but they are quite less as compared to acetaminophen control rats. Very few damaged cells around centrilobular portion of tissue can be seen (Fig. 2d). The rats pretreated with silymarin $(35 \mathrm{mg}$ ) prior to acetaminophen administration showed almost complete protection against injury. It showed recovery with no fatty deposition. Hepatic cells and sinusoids appeared to be normal with minimal portal inflammation (Fig. 2e).

\section{Discussion}

Presence of polysaccharides in seaweeds has been reported for various biological activities including cholesterol lowering, immunomodulatory, In vitro and In vivo anti-hepatotoxic activity $[23,24]$ and antiproliferative activity [25]. Seaweeds contain commercially important polysaccharides, named as agar, fucoidan, alginate, carrageenan, laminaran and sulphated galactan [12]. In the present study intoxication of acetaminophen (AAP) in experimental rats caused liver damage as evident from the increase in the level of hepatic enzymes; AST, ALT, ALP and LDH along with increase in serum bilirubin, glucose, triglycerides, urea and creatinine. It is well established that when the liver is injured as a result of introduction of infectious agents or chemicals, the serum levels of GPT (ALT) and GOT (AST) are raised significantly [26], along with leakage of ALP and LDH [27] reflecting the severity of liver injury [28]. In present study the treatment with both fractions of crude sulphated polysaccharides, $\mathrm{EW}_{1}$ and $\mathrm{EW}_{2}$ fraction of Sargassum swartzii significantly $(p<0.05)$ reduced the elevated level of ALT, AST, ALP, and LDH and all other biochemical parameters. The highest activity was found in $\mathrm{EW}_{1}$ fraction of $S$. swartzii. All parameters including liver marker enzymes, bilirubin, triglycerides, cholesterol and urea were statistically equal in both silymarin and $\mathrm{EW}_{1}$ fraction of $S$. swartzii in acetaminophen-induced liver injury. Silymarin regenerates liver tissues, help in protein synthesis, reverses glutathione

Table 2 Effect of Crude Sulphated Polysaccharides of Sargassum swartzii on Glucose, Urea, Creatinine, Triglycerides and Cholesterol in Acetaminophen-Intoxicated Rats

\begin{tabular}{llllll}
\hline Groups & Glucose $(\mathrm{mg} / \mathrm{dl})$ & Triglycerides $(\mathrm{mg} / \mathrm{dl})$ & Cholesterol $(\mathrm{mg} / \mathrm{dl})$ & Urea $(\mathrm{mg} / \mathrm{dl})$ & Creatinine $(\mathrm{mg} / \mathrm{dl})$ \\
\hline Normal control & $108.6^{\mathrm{c}} \pm 3.5$ & $84^{\mathrm{b}} \pm 5.2$ & $84.6^{\mathrm{a}} \pm 2.3$ & $30^{\mathrm{d}} \pm 1$ & $0.9^{\mathrm{c}} \pm 0.1$ \\
Acetaminophen (AAP) control & $162^{\mathrm{a}} \pm 6.5$ & $167.3^{\mathrm{a}} \pm 10.06$ & $64.6^{\mathrm{bc}} \pm 5.8$ & $64^{\mathrm{a}} \pm 6.2$ & $1.23^{\mathrm{a}} \pm 0.11$ \\
Silymarin (35 mg/kg) + AAP & $118.3^{\mathrm{bc}} \pm 8.6$ & $92^{\mathrm{b}} \pm 23.06$ & $68.6^{\mathrm{b}} \pm 4.04$ & $35^{\mathrm{cd}} \pm 2.6$ & $1.03^{\mathrm{bc}} \pm 0.057$ \\
S. swartzii EW + AAP & $127^{\mathrm{b}} \pm 7.5$ & $108^{\mathrm{b}} \pm 17.08$ & $65^{\mathrm{ac}} \pm 3.6$ & $38.6^{\mathrm{bc}} \pm 2.5$ & $1^{\mathrm{bc}} \pm 0.1$ \\
S. swartzii EW & $169^{\mathrm{a}} \pm 8$ & $106^{\mathrm{b}} \pm 13.11$ & $58.3^{\mathrm{c}} \pm 3.7$ & $43.6^{\mathrm{b}} \pm 2.08$ & $1.1^{\mathrm{ab}} \pm 0$ \\
\hline
\end{tabular}

The values are expressed as means \pm Standard error ( $n=6$ animals per group)

The values having the same superscript within the column are not significantly $(p<0.05)$ different according to Duncan's multiple range test 


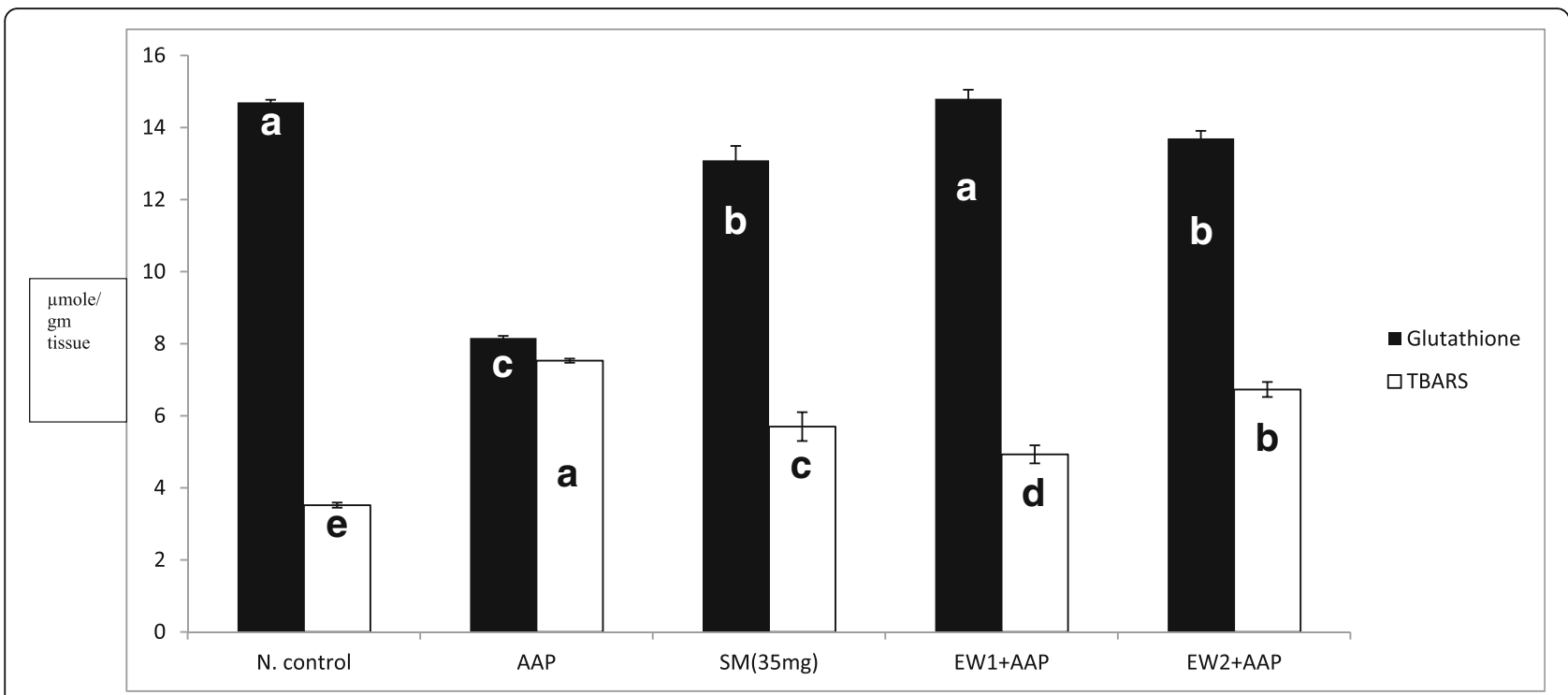

Fig. 1 Effect of Crude Sulphated Polysaccharides of Sargassum swartzii on Glutathione and Lipid Peroxidation (TBARS) in Acetaminophen Intoxicated Rats. The vertical lines in the bars showing means \pm Standard error ( $n=6$ animals per group).The values having the same superscript on the bars of same color are not significantly $(p<0.05)$ different according to Duncan's multiple range test. N. control= Normal control, $\mathrm{AAP}=$ Acetaminophen, SM Standard Drug Silymarin, EW1 $=$ Extracted with water at room temperature, EW2 $=$ Extracted with water at $70^{\circ} \mathrm{C}$

fall in tissue, enhanced glucuronidation and reduced inflammation, hence it acts as antioxidant, antifibrotic, anti-inflammatory, membrane stabilization and immunomodulatory agent [29]. In current study the crude sulphated polysaccharides $\left(\mathrm{EW}_{1}\right)$ extracted at room temperature showed its maximum protective effect might be due to its antioxidant properties and presence of higher concentration of sulphated polysaccharide as reported by Ponce et al. [19] in a brown seaweed Adenocystis utricularis. They have reported $30 \%$ sulphate in $\mathrm{EW}_{1}$ as compared to $8 \%$ in $\mathrm{EW}_{2}$. Vijayabaskar et al. [30] reported antioxidant activity of Sargassum swartzii due to presence of $10.43 \%$ crude sulfated polysaccharide in seaweed. The hepatoprotective effect of crude sulphated polysaccharides have also been reported by other researchers [31-33]. The sulphated polysaccharides from Sargassum polycystum showed protective effect against paracetamol induced toxic hepatitis in rats [31]. Ross et al. [33] also reported that sulphated polysaccharides from Sargassum siliquosum produced hepatoprotective activity against acetaminophen induced liver damage. Sulphated polysaccharides have ability to inhibit viral replication against HIV, hepatitis and herpes viruses [11], to stimulate immune system [14] and to protect against hepatocellular carcinomas [34], may be due to the prevention of increased pro-inflammatory cytokines, IL-6 and IL-12 [35].

Glutathione is most abundant tripeptide endogenous antioxidant present in liver. It protects liver by binding with reactive metabolites formed by AAP, thus preventing their covalent binding with liver proteins. Glutathione helps in scavenging free radical species and maintenance of membrane protein thiols [36]. Taye \& Abdel-Raheem, [37] reported significant reduction in GSH level of kidney and lungs tissues after $\mathrm{CCl}_{4}$ intoxication. Other researcher also proved the significant decrease in the GSH content in different organs of rats when injected with $\mathrm{CCl}_{4}$ [38]. The rats pretreated with crude polysaccharides $\left(\mathrm{EW}_{1}\right.$ and $\mathrm{EW}_{2}$ fraction) of S. swartzii significantly ameliorated the acetaminophen-induced reduction in glutathione level. The glutathione status of body was significantly improved and lipid peroxidation was reduced in rats pretreated with crude polysaccharides extracted at room temperature ( $\mathrm{EW}_{1}$ fraction) when compared to silymarin $(35 \mathrm{mg} / \mathrm{kg})$ pretreated rats intoxicated with acetaminophen. The polysaccharides present in seaweeds prevent the elevation of pro-inflammatory cytokines IL-6 and IL-12 [35] and showed hepatoprotective effect $[17,31]$. The sulphated polysaccharides from S. wightii restored the disturbed level of hepatic enzymes, antioxidant enzymes (superoxide dismutase, catalase, glutathione peroxidase), non-enzymatic antioxidants (glutathione, vitamin $\mathrm{C}$ and $\mathrm{E}$ ), lipid peroxidation, protein carbonyls and ATPases [32]. Kawano et al. $[39,40]$ reported that dietary fiber from Laminaria sp., Sargassum fulvellum and Eisenia bicyclis have ability to suppress D-galactosamine (D-GalN)-induced liver malfunction, might be due to the presence of fucoidan. The crude sulphated polysaccharides from Laminaria japonica and Ulva lactuca have ability to improve liver function by scavenging free radicals [41-43]. 

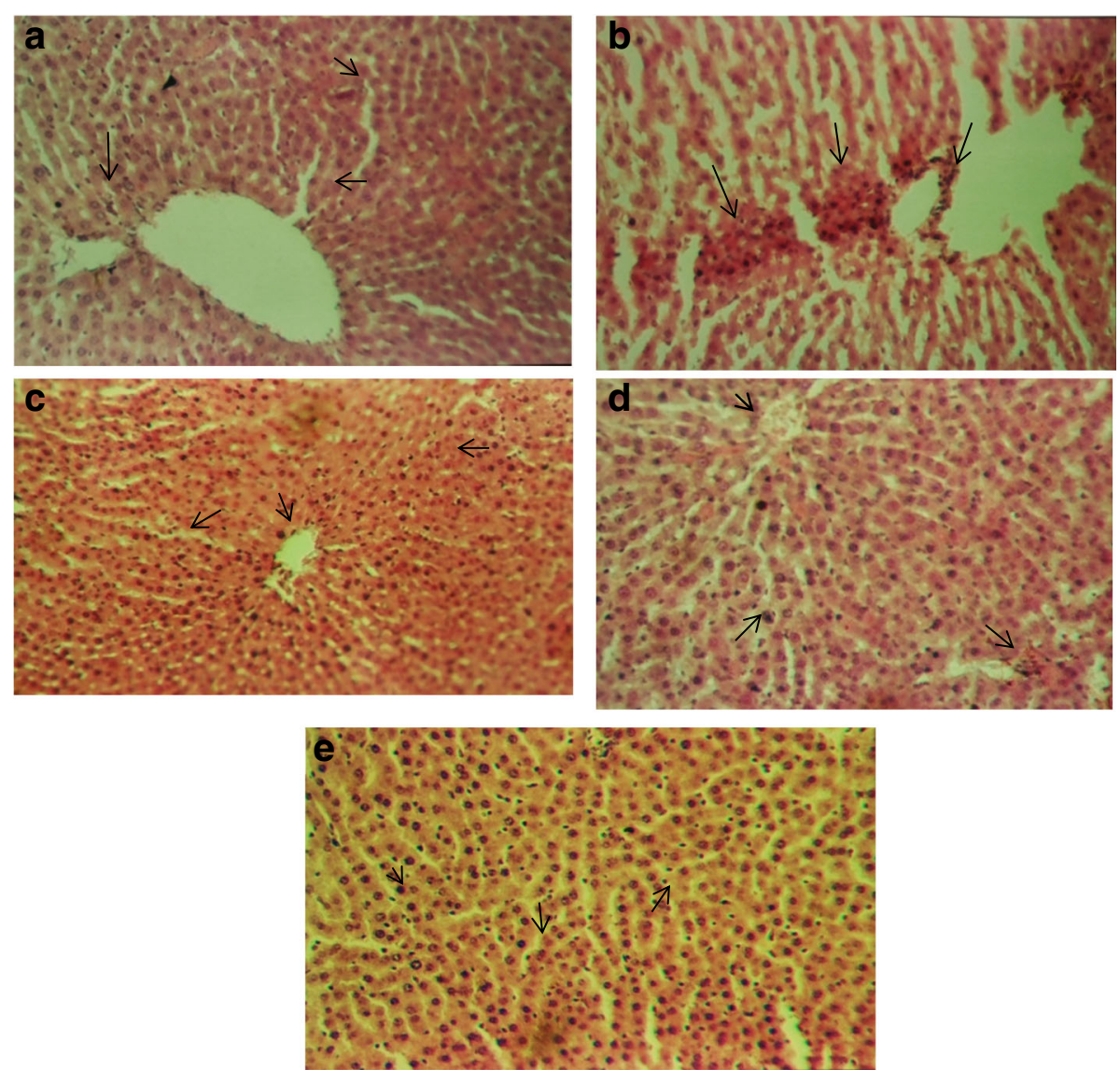

Fig. 2 Histopathological studies showing architecture of rats liver tissues in different pretreated groups. Magnification; 100X and 200X. a. Light micrograph of normal liver cells. b. Acetaminophen (AAP) treated rats. c. EW1 fraction of S. swartzii + AAP. d. EW2 fraction of S. swartzii +AAP. e. Liver cells of silymarin +AAP

The intraperitoneal administration of acetaminophen caused marked hepatic necrosis with fatty changes, infiltration of polymorphonuclear cells, abnormal central vein and sinusoidal morphological pattern. Crude sulphated polysaccharides from S. swartzii $\left(\mathrm{EW}_{1}\right.$ fraction) showed considerable reduction in pathological changes that produced after acetaminophen administration. The sulphated polysaccharides from S. swartzii extracted at room temperature $\left(\mathrm{EW}_{1}\right.$ fraction) prevented hepatic necrosis similar to the rats pretreated with silymarin $(35 \mathrm{mg} / \mathrm{kg})$ in acetaminophen-intoxicated rats. Raghavendran \& Srinivasan [17], reported that a number of necrotic cells were depleted in rats co-treated with sulphated polysaccharides and acetaminophen. This might be due to the presence of high sulfate content in seaweed polysaccharides, which inhibit oxidative stress [44]. Ross et al. [33] reported that administration of sulphated polysaccharides from Sargassum siliquosum produced mild hepatocellular degeneration suggesting their protective role. The sulphated polysaccharides from Sargassum wightii showed considerable reduction in the pathological changes produced after cyclosporine A-induced liver injury animals [32]. This protective action may possibly be due to its effect of preserving the cellular membrane of the hepatocytes from breakage by the reactive metabolites [45]. The sulphated polysaccharides extracted at room temperature and at $70^{\circ} \mathrm{C}$ had completely different chemical compositions [19].

\section{Conclusion}

Nature based treatment of liver diseases has gained tremendous attention worldwide in past few decades. Seaweeds have characteristic of having unique polysaccharides in their cell walls that are not found in land plants. Current study has focused on the extraction of polysaccharides and their hepatoprotective role as polysaccharides are assumed to be good antioxidants. Results of present study showed that polysaccharides extracted at room temperature ( $E_{1}$ fraction) from Sargassum swartzii have reduced the acetaminophen attenuated disturbed liver marker enzymes and other biochemical parameters, supported by histopathological findings. The polysaccharides from Sargassum swartzii also increased 
the antioxidant status of body. This study suggests that crude polysaccharide of $S$. swartzii has ability to protect against liver toxicity similar and/or better than silymarin (a standard drug). However toxicological studies would be recommended to evaluate any toxic effect of Sargassum swartzii.

\author{
Abbreviations \\ AAP: Acetaminophen; ALP: Alkaline phosphatase; ALT: Alanine \\ aminotransferases; AST: Aspartate aminotransferases; DTNB: 5,5'-Dithiobis-2- \\ nitrobenzoic acid; EW $\mathrm{EW}_{1}$ : Polysaccharides extracted at room temperature; \\ $\mathrm{EW}_{2}$ : Polysaccharides extracted at $70^{\circ} \mathrm{C}$; GSH: Glutathione; GSH: Hepatic \\ glutathione; H \& E: Hematoxylin and eosin; LDH: Lactate dehydrogenase; \\ MDA: Malondialdehyde; TBA: Thiobarbituric acid; TCA: Trichloroacetic acid; \\ w.l.t.: Wet liver tissue
}

\section{Acknowledgements}

They are also thankful to the Dr. Aisha Begum, Assistant professor, Department of Botany for their kind help in identification of seaweed.

\section{Funding}

Authors are thankful to the Dean, Faculty of Science, University of Karachi for fincial assistance.

\section{Availability of data and materials}

Research data (Lab notebook) and materials can be provided on request.

\section{Authors' contributions}

KH \& VS conceived and designed the study. KH performed experimental work. KH \& SE analyzed and interpreted the results. NK supervised histo-pathological work. KH wrote the manuscript. KH, SE \& JA improved the manuscript. All authors read and approved the final manuscript.

\section{Ethics approval}

The experiment was conducted according to the rules of Institutional Animal Ethics Committee (IAEC), University of Karachi.

\section{Consent for publication}

Not applicable.

\section{Competing interests}

The authors declare that they have no competing interests.

\section{Publisher's Note}

Springer Nature remains neutral with regard to jurisdictional claims in published maps and institutional affiliations.

\section{Author details}

'Biotechnology \& Drug Development Laboratory, Department of Biochemistry, University of Karachi, Karachi 75270, Pakistan. ${ }^{2}$ Department of Zoology, University of Karachi, Karachi 75270, Pakistan. ${ }^{3}$ Department of Food Science \& Technology, University of Karachi, Karachi 75270, Pakistan. ${ }^{4}$ Agricultural Biotechnology \& Phytopathology Laboratory, Department of Botany, University of Karachi, Karachi 75270, Pakistan.

\section{Received: 19 October 2018 Accepted: 30 January 2019}

Published online: 13 February 2019

\section{References}

1. Hira K, Sultana V, Ara J, Ehteshamul Haq S, Athar M. Hepatoprotective potential of three Sargassum species from Karachi coast against carbon tetrachloride and acetaminophen intoxication. J Coast Life \& Med. 2016;4: $10-3$.

2. Muriel P, Rivera-Espinoza Y. Beneficial drugs for liver diseases. J Appl Toxicol. 2008;28:93-103.

3. Hong M, Li S, Tan HY, Wang N, Tsao N-W, Feng Y. Current status of herbal medicines in chronic liver disease therapy: the biological effects, molecular targets and future prospects. Int J Mol Sci. 2015;16:28705-45.
4. Seeff LB, Lindsay KL, Bacon BR, Kresina TF, Hoofnagle JH. Complementary and alternative medicine in chronic liver disease. Hepatol. 2001;34:595-603.

5. Samee H, Li ZX, Khalid J, Guo YC. Anti-allergic effects of ethanol extracts from brown seaweeds. J Zhejiang Univ Sci B. 2009:10:147-53.

6. Rasmussen RS, Morrissey MT. Marine biotechnology for production of food ingredients. Adv Food Nutr Res. 2007;52:237-92.

7. Tabarsa M, Rezaei M, Ramezanpour Z, Waaland JR. Chemical composition of the marine algae Gracilaria salicornia (Rhodophyta) and Ulva lactuca (Chlorophyta) as a potential food source. J Sci Food Agric. 2012;92:2500-6.

8. Abdel-Rahman MK, El-Megeid AAA. Hepatoprotective effect of soapworts (Saponaria officinalis) pome granate Peel. (Punica granatum L.) and cloves (Syzygium aromaticum L.) on mice with $\mathrm{CCl}_{4}$ hepatic intoxication. World. J Chem. 2006;1:41-6.

9. Yuan $\mathrm{V}$, Bone DE, Carrington MF. Antioxidant activity of dulse (Palmaria palmata) extract evaluated in vitro. Food Chem. 2005;91:485-94.

10. Ananthi S, Raghavendran HR, Sunil AG, Gayathri V, Ramakrishnan G, Vasanthi HR. In vitro antioxidant and in vivo anti-inflammatory potential of crude polysaccharide from Turbinaria ornata (marine brown algae). Food Chem Toxicol. 2010;48:187-92.

11. Kim S-K. Handbook of marine macroalgae: biotechnology and applied phycology. Chichester. UK: Wiley-Blackwell; 2011.

12. Li B, Lu F, Wei X, Zhao R. Fucoidan: structure and bioactivity. Molecules. 2008:13:1671-95.

13. Chen $H$, Yan X, Zhu P, Lin J. Antioxidant activity and hepatoprotective potential of Agaro-oligosaccharides in vitro and in vivo. Nutr J. 2006;5:31.

14. Lebedynskaya EA, Makarenkova ID, Lebedynskaya OV, Akhmatova NK, Zvyagintseva TN. Effect of sulfated polysaccharides from brown seaweed Laminaria japonica on the morfology of lymfoid organs and functional characteristics of immunocompetent cells. Biomed Khim. 2014;60:581-90.

15. De Souza MCR, Marques CT, Dore CMG, De Silva FRF, Rocha HAO, Leite EL. Antioxidant activities of sulfated polysaccharides from and red seaweeds. J Appl Phycol. 2007;19:153-60.

16. Raghavendran HB, Sathival A, Devaki T. Antioxidant effect of Sargassum polycystum (Phaeophyceae) against acetaminophen-induced changes in hepatic mitochondrial enzymes during toxic hepatitis. Chemosphere. 2005;61:276-81

17. Raghavendran HB, Srinivasan P. Effect of crude sulphated polysaccharide from brown algae against acetaminophen-induced toxicity in rats. Can J Physiol Pharmacol. 2008;86:660-6.

18. Smit AJ. Medicinal and pharmaceutical uses of seaweed natural products: a review. J Appl Phycol. 2004;16:245-62.

19. Ponce NMA, Pujol CA, Damonte EB, Flores ML, Stortz CA. Fucoidans from the brown seaweed Adenocystis utricularis extraction methods, antiviral activity and structural studies. Carbohydr Res. 2003;338:153-65.

20. Samarth RM, Panwar M, Kumar M, Soni A, Kumar M, Kumar A. Evaluation of antioxidant and radical-scavenging activities of certain radioprotective plant extracts. Food Chem. 2008;106:868-73.

21. Ohkawa H, Ohishi N, Yagi K. Assay for lipid peroxides in animal tissues by thiobarbituric acid reaction. Anal Biochem. 1979:95:351-8.

22. Armitage P, Berry G. Statistical methods in medicinal Research. $3^{\text {rd }}$ ed. Oxford: Blackwell Scientific publications; London; 1994. p. 620.

23. Lahaye M, Ray B. Cell wall polysaccharides from the marine green algae Ulva rigida (Ulve les Chlorophyta)-NMR analysis of Ulvan oligosaccharides. Carbohydr Res. 1996;22:161-73.

24. Leiro JM, Castro R, Arranz JA, Lamas J. Immunomodulating activities of acidic sulfated polysaccharides obtained from the seaweeds Ulva rigida C. Agardh. Int Immunopharmacol. 2007;7:879-88.

25. El-Baky HHA, El-Baz FK, El-Baroty GS. Potential biological properties of sulphated polysaccharides extracted from the macroalgae Ulva Lactuca L. Academic j Cancer Res. 2009;2:1-11.

26. Zhang $S$, Lu B, Han X, Xu L, Qi Y, Yin L, Xu Y, Zhao Y, Liu K, Peng J. Protection of the flavonoid fraction from Rosa laevigata Michx against carbon tetrachloride-induced acute liver injury in mice. Food Chem Toxicol. 2013:55:60-9.

27. Setty RS, Quereshi AA, Swamy AH, Patil T, Prakash T, Prabhu K. Hepatoprotective activity activity of Calotropis procera flowers against paracetamol-induced hepatic injury in rats. Fitoterapia. 2007;78:451-4.

28. Lin SC, Yao CJ, Lin CC, Lin YH. Hepatoprotective activity of Taiwan folk medicine, Eclipta prostrate Linn. Against various hepatotoxins induced acute toxicity. Phytother Res. 1996;10:483-90. 
29. Pradhan SC, Girish C. Hepatoprotective herbal drug, silymarin from experimental pharmacology to clinical medicine. Indian J Med Res. 2006;124:491-504.

30. Vijayabaskar P, Vaseela N, Thirumaran G. Potential antibacterial and antioxidant properties of a sulfated polysaccharide from the brown marine algae Sargassum swartzii. Chin J Nat Med. 2012;10:421-8.

31. Raghavendran HB, Sathivel A, Yogeeta RSSK, Devaki T. Efficacy of Sargassum polycystum (Phaeophyceae) sulphated polysaccharide against paracetamolinduced DNA fragmentation and modulation of membrane-bound phophatases during toxic hepatitis. Clin Exp Pharmacol Physiol. 2007:34:142-7.

32. Josephin A, Nithya K, Amudha G, Veena K, Preetha SP, Varalakshmi P. Role of sulphated polysaccharides from Sargassum wigtii in cyclosporine A-induced oxidative liver injury in rats. BMC Pharmacol. 2008;8:4.

33. Ross V, Joven A, Donnie RJ, Marianne M, Katherine $P$, Carla P, Charm P, Jose P. Hepatoprotective effects of aqueous sulfated polysaccharide extract from Sargassum siliquosum J.G. Agardh on paracetamol-induced oxidative liver toxicity and antioxidant properties. Int J Pharm Front Res. 2012;2:15-27.

34. Hayakawa K, Nagamine T. Effect of fucoidan on the biotinidase kinetics in human hepatocellular carcinoma. Anticancer Res. 2009;4:1211-7.

35. Raghavendran HRB, Srinivasan P, Rekha S. Immunomodulatory activity of fucoidan against aspirin-induced gastric mucosal damage in rats. Int Immunopharmacol. 2011;11:157-63.

36. Kumar A, Rai N, Kumar N, Gautam P, Kumar JS. Mechanism involve in hepatoprotection of different herbal products. Int I Res Pharm Sci. 2013;4:112-7.

37. Taye A, Abdel-Raheem IT. Hepatoprotective effect of the selective mineralocorticoid receptor antagonist, eplerenone against carbon tetrachloride induced liver injury in rats. Ann Hepatol. 2012;11:384-91.

38. Ohta $Y$, Kongo $M$, Sasaki E. Therapeutic effect of melatonin on carbon tetrachloride-induced acute liver injury in rats. J Pineal Res. 2000;28:119-26.

39. Kawano N, Sanada EY. Effect of dietary fiber in edible seaweeds on the development of D-Galactoseamine-induced hepatopathy in rats. J Nutr Vitaminol. 2007a;53:446-50

40. Kawano N, Egashira Y, Sanada H. Effects of various kinds of edible seaweeds in diets on the development of D-galactosamine induced hepatopathy in rats. J Nutr Sci Vitaminol. 2007b;53:315-23.

41. Zhao X, Xue C-H, Li Z-J, Cai Y-P, Liu H-Y, Qi H-T. Antioxidant and hepatoprotective activities of low molecular weight sulfated polysaccharides from Laminaria japonica. J Appl Phycol. 2004;16:111-5.

42. Qi H, Zhang Q, Zhao T, Hu R, Zhang K, Lia Z. In vitro antioxidant activity of acetylated and benzoylated derivatives of polysaccharide extracted from Ulva pertusa (Chlorophyta). Bioorg Med Chem Lett. 2006;16:2441-5.

43. Sathivel A, Raghavendran HB, Srinivasan P, Devaki T. Anti-peroxidative and anti-hyperlipidemic nature of Ulva lactuca crude polysaccharide on DGalactosamine induced hepatitis in rats. Food Chem Toxicol. 2008:46:3262-7.

44. Ruperez P, Ahrazem O, Leal JA. Potential antioxidant capacity of polysaccharide from the edible marine brown seaweed Fucus vesiculosus. J Agric Food Chem. 2002;50:840-5.

45. Raghavendran HB, Sathivel A, Devaki T. Hepatoprotective nature of seaweed alcoholic extract in acetaminophen-induced hepatic oxidative stress. J Health Sci. 2004;50:42-5.

\section{Submit your manuscript to a SpringerOpen ${ }^{\circ}$ journal and benefit from:}

- Convenient online submission

- Rigorous peer review

- Open access: articles freely available online

- High visibility within the field

- Retaining the copyright to your article

Submit your next manuscript at $\boldsymbol{\nabla}$ springeropen.com 